S. A. PROKOPENKO ${ }^{1,2}$, Professor, Doctor of Engineering Sciences, sibgp@mail.ru

Yu. V. LESIN ${ }^{3}$, Professor, Doctor of Engineering Sciences

A. A. $\mathbf{L I}^{2}$, Academic Secretary, Professor, Doctor of Engineering Sciences

V. G. SHADRIN ${ }^{4}$, Associate Professor, Candidate of Engineering Sciences

${ }^{1}$ Tomsk Polytechnic University, Tomsk, Russia

${ }^{2}$ VostNII Science Center, Kemerovo, Russia

${ }^{3}$ Gorbachev Kuzbass State Technical University, Kemerovo, Russia

${ }^{4}$ Kemerovo State University, Kemerovo, Russia

\title{
DIALECTICAL CONTRADICTIONS AND RESOLUTIONS TOWARD INNOVATIVE DEVELOPMENT AND ECOLOGICAL SAFETY ENHANCEMENT IN MODERN-DAY COAL MINING
}

\section{Introduction}

The area in the lithosphere under mining contains a variety of georesources as a rule: a substance of the subsoil (solid, liquid, gaseous, mixture); underground space (cavities, voids); energy of the subsoil (static, geodynamic, geomagnetic). For example, in Kuzbass, the coal-bearing strata are represented by coal seams and series of various composition, quality and thickness; layers of coarse-, medium and fine-grained sandstone with binding of different composition and strength; siltstone and mudstone of various rank and thickness. The coal-bearing strata are overlaid with loose quaternary deposits (clay and clay loam) to 30-40 m thick, covered by a fat soil layer $0.5-1.2 \mathrm{~m}$ in thickness. Coal seams are complex natural formations containing organic matter, abundance of gases and rare earth elements. Gas content of the Kuzbass coal seams reaches $25-30 \mathrm{~m}^{3} / \mathrm{t}$ and more. The content of rare earth elements sometimes reaches commercial concentrations [1]. The lithosphere contains numerous aquifers with different depths of occurrence, water contents and compositions. The huge energy potential of the crust is displayed by earthquakes and rock bursts which unload subsoil from the accumulated energy and are increasingly more frequently observed in Siberia in recent years.

The available knowledge and technologies of solid mineral mining bewitch mining engineers by the progress history of the mining art, by the technical excellence and high mechanization, automation and digitalization, on the one hand, while, on the other hand, depress by the lack of resource efficiency and environmental friendliness. A modern coal mine underimplements the geo-resource potential of a subsoil area, neglecting and loosing considerable natural capacities. Mining territories often look like zones of ecological disaster.
The incremental coal production raises ecological tension in the coal mining areas. Environmental measures only allow minor mitigation of the impact. This study aims to disclose the deep causes of the adverse condition of the coal mining regions and to find innovative resources for the improvement of the ecological situation.

The analysis and understanding of understanding between a human being and the crust in the course of solid mineral mining has revealed dialectical contradictions in activities of mines. The hierarchical arrangement and scrutiny of the contradictions show that mines poorly use resource potential of mineral deposits due to technological and economic underdevelopment of nal processing, while the major portion of georesources falls in the category of waste. The cur-

The situation in existence in mineral mining to be modified calls for the resolution of the dialectical contradictions and for the breakthrough innovations. One of the latter may be the change in the operational policy of a mine with replacement of coal flow by the flow of energy fluids. This will release a mining area from the whole range of adverse ecological and economic impacts. The change of the operational policies of coal mines is the top-priority objective of ining engineers, as well as scientists and practitioners in mining, and presses for the build-up igent and innovative potential. Such advancement is possible through resolution of other dialectical contradictions the essence of which is planned to be disclosed in the framework of the further research.

Key words: coal mine, ecology, georesource, dialectical contradictions, resolution, mining engineers, innovation, potential, technology, product, waste, dump, commodity.

DOI: 10.17580/em.2020.01.16 
natural rocks in composition, structure and properties. Haulage equipment and dumping technologies produce stockpiles of different shape, height, structure and volume. This affects prospects of future management of mining waste.

This study aims to find the deeper causes (philosophy) of poor condition of the coal mining territories and to reveal the innovative upside potential of ecological situation.

\section{Research methodology and methods}

The research focuses on the disclosure of the ecology-technology-dialectics connection in performance of coal mines. The causes of mining imperfection were disclosed through dialectic cognition of antagonisms between extremes shaping a coal mine. The principles of nature-like technologies were studied based on the methodological framework for the homeostatic regulation of nature-andtechnology systems [3]. Systematization of dialectical contradictions within a mine used the methods of scientific analysis and synthesis of objects and phenomena in mining. The generalization of the known technologies of secondary processing (hereinafter re-processing) revealed connections and ways of enhancing resource-use efficiency in coal mining.

\section{Results and discussion}

Studies into the causes of low efficiency in the mining and processing industry display the problem as a consequence of some dialectical contradictions of physical, technological and economic nature, which accompany mineral mining and fail to find any good solution. This section discusses the key contradictions in resource-efficiency and ecology.

A mine is a unity of a subsoil area intended for mineral mining, on the one hand, and a mining technology, on the one hand.

The contradictory character of the technology-and-subsoil interaction is governed by the relationship between an object and a tool of development. Schopenhauer identifies the inner essence of anything as will to live in its objectification and striving for existence [9]. The present study authors think the essence of our planet consists in striving for preservation of existence and integrity and for prevention of destruction and invasion. In the meanwhile, the essence of mining technologies lies in striving for destruction of the lithosphere and its extraction by parts to ground surface. These essences enter the first-type dialectical contradiction (DC), namely, toolobject DC 1 (Fig. 1).

The planet aversely gives way to destruction and forces a human being to execute much work in this respect, including removal of huge quantities of gangue, water and gases. High strength of the earth stratum prevents penetration, erodes and breaks tools (shovels, excavators, dump trucks, conveyors, etc.) and quickly turns them into metal, rubber and other waste.

At the same time, a mine shows the unity of a natural matter (medium) and an altered matter. The earth interior is occupied by a dense and solid natural substance saturated with water and dissolved gases. The natural matter strives for preservation of the original nature while the technosphere

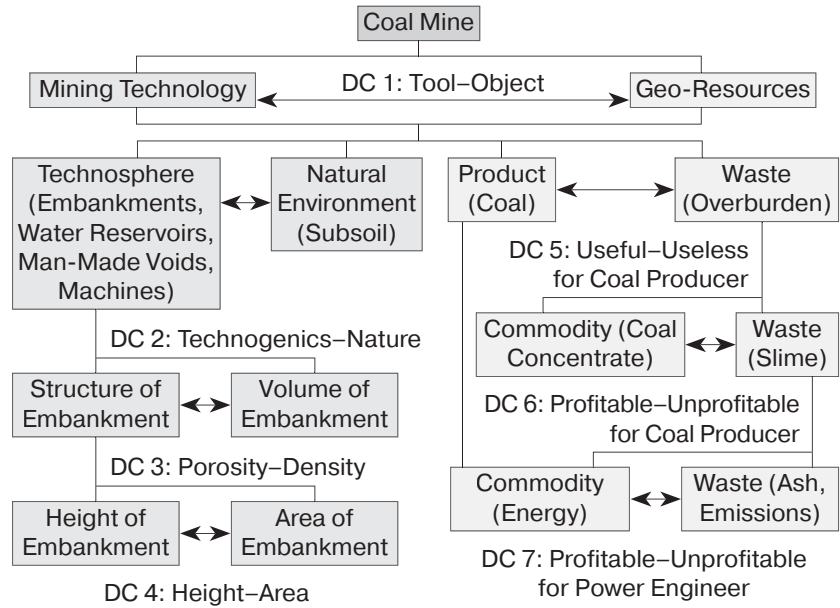

Fig. 1. Hierarchy of principal dialectical contradictions in coal mining

represented by man-made voids, embankments and water reservoirs attacks, transforms and diminishes the natural matter.

The anthropogenic mining activities intrude the three major natural media or shells of the planet: lithosphere, hydrosphere and cosmosphere. Removal of coal results in the formation of cavities and voids in the earth stratum, extracted rocks are placed on the ground surface in embankments, and pumping of water from underground and surface mines initiates formation of sinks in aquifers and at grass, which changes local hydrography. The natural matter resists formation of man-made cavities in the lithosphere by falling roof rocks and sidewalls, or by flooding. Waste dumps (to 200-300 $\mathrm{m}$ and to 3-4 long) and water reservoirs (to hundred hectares in area) disturb ground air flows, increase evaporation, change air humidity and transform thermal conditions in the area. The ground water lowering brings dehydration and drying of land. Resisting the penetration, the planet induces slope falls, fine dusting, embankment failures and draining of water bodies. This is the second-type DC 2 between the natural media and man-made structures, namely, naturetechnogenics. The technogenics is understood in this study as structures erected in the course of mineral mining. In contrast to the technosphere, the technogenics includes no mining machines and devices. The contradiction lies in the fact that the man-made structures occupy and diminish the natural media while the latter strive for preservation of the interior. The response of the natural media is the cause of numerous accidents in mines.

Placement of broken matter in fills and embankments on ground surface causes new dialectical contradictions. Fragmentation of the earth stratum into shapeless and different size particles by disintegration and blasting disables formation of small-size, compact and strong man-made masses of greater height on ground surface and reduces land parcel. Porosity of such fills reaches $25-30 \%$. The loose structure governs the greater volume of a fill. Contradiction DC 3 exists between the structure and volume of a fill. The nonefficiency of the porosity-density relationship prevents from reducing the fill volume and mitigating the environmental impact. 
Given the current dumping technologies in surface and underground mining, loose and coarse rocks are piled at an angle of rest on the ground surface and occupy large areas. Here we have DC 4 between the height and area of a dump: the increase in its height is unaccompanied with the decrease in its bottom area.

Resolution of conflicts DC 3 and DC 4 is possible through the transition from the chaotic to ordered destruction of the lithosphere. It is more rational to separate rocks from rock masses by large $(2 \times 2 \times 2 \mathrm{~m})$ cubic or parallelepipedic blocks by analogy with blocks in the Pyramids. Compact laying of such blocks will form a mass with physical properties similar to a natural matter. With such approach, rocks removed from a surface or underground mine become a commodity, for instance, for building strong foundations, basements and structures, etc. Furthermore, it becomes possible to create artificial hilly landscapes suitable for development, mountain skiing and rock climbing, and camping. These objectives are achievable with the strategic approach of an individual and a government to mineral resources and with the relevant responsibility for the post-mining area.

Improvement of mining technologies currently under way using conventional methods fails to provide sensible reduction in mining waste, in extent of mining and haulage or in environmental impact. The fundamental change in the mining activities is required to that end.

In open pit mining of steeply dipping and sloping coal seams, a breakthrough solution can be the transition of mining front from the current lateral to transverse arrangement relative to seams, with stage-wise increase in the mining depth and with placement of waste in the mined-out void. The bulk of extracted waste rocks can be placed within the limits of a mining license area in this case $[10,11]$. The haulage distances, the number of dump trucks and the atmospheric pollution due to emissions are reduced as a result. The dumping-disturbed land area is minimized, and the size of the land use is decreased many times. A downtrend in capacity of an open pit mine in case of the transition to such technology is no more a constraint and impediment for the change. The community in coal mining regions is increasingly more concerned with reduction in coal production by open cut mining, and the decrease in the coal output in Kuzbass in 2019 is deemed as a blessing for people and nature. Technological advance in coal mining has been a topic of discussions for more than 30 years, and is yet neglected by the Russian industry while its engineering potential is vanishing due to reduction in R\&D personnel.

Even greater abatement in ecological and industrial risk of coal mining is plausible with transition from destructive to sparing development of subsoil. For example, in case of extraction of energy potential of coal seams without their disintegration and lifting to ground surface [12]. This can be a resolution of the tool-object contradiction (Fig. 2).

The flow of coal fragments from the subsoil is replaced by the flow of energy fluids (producer gas, high-temperature steam) to be converted on the ground surface to electrical power by small thermal power plants. Abandonment of coal extraction in favor of in-situ energy extraction from them opens a high way for the rise in the mining economy and

\begin{tabular}{|c|c|}
\hline Object (Rock Mass) & Tool (Oxidizer) \\
\hline Dialectical Opposites \\
\hline Mine of the Future \\
\hline
\end{tabular}

Philosophy: Turn a Coal Seam to a Flow

of Energy Fluids to Ground Surface

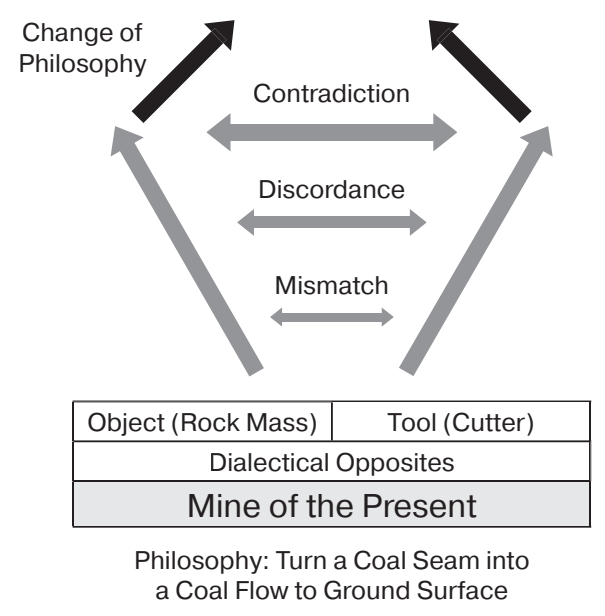

Fig. 2. Fundamental renovation of essence of coal mine

environmental friendliness. The proposed method of underground energy "mining" is the implementation of the intelligent breakthrough in engineering and the next-level innovative technological advance in in-situ coal gasification [13, 14] with appreciable enhancement of energy efficiency of the activities.

Another cause of imperfection in the present-day coal production is economical contradictions (Fig. 3). The first conflict is between the dialectical contradictions of a georesource-a product and waste. The essence of DC 5 lies in the usefuluseless relationship for a coal producer. Useful is interpreted as something clearly suitable for commercial or social application, useless is something without any currently visible prospect for application.

As mining technologies and industries are advanced, more and more georesources should be converted to useful products with reduction in useless waste. At the same time, the persistent increase in the mining depths, coal outputs and mine capacities, etc. leads to the annual increment in the mining waste, either overburden, water or gas [15]. As a rule, a multibranch structure of economy in the mining regions is unfavorable for the integrated subsoil development. As early as 20 years ago, production of 1 ton of coal in Kuzbass by open pit mining required removal of 3-4 $\mathrm{m}^{2}$ of overburden rocks, and the current volume of overburden to be stripped is $6-8 \mathrm{~m}^{3}$ or even $10-15 \mathrm{~m}^{3}$. The volume of process water pumped out of open pit mines has increased from $2-6$ to $8-13 \mathrm{~m}^{3} / \mathrm{t}[16,17]$. Kuzbass mines produce around 80 million tons of coal every year and emit 1.5-2.0 billion cubic meters of methane in the atmosphere [18]. Such operation requires many main and auxiliary fans, which dictates construction of longer piping, causes high power consumption and exerts adverse effect on the cosmosphere.

At the stage of a mine planning and design, it is known what is useful target within the mining license area and what 


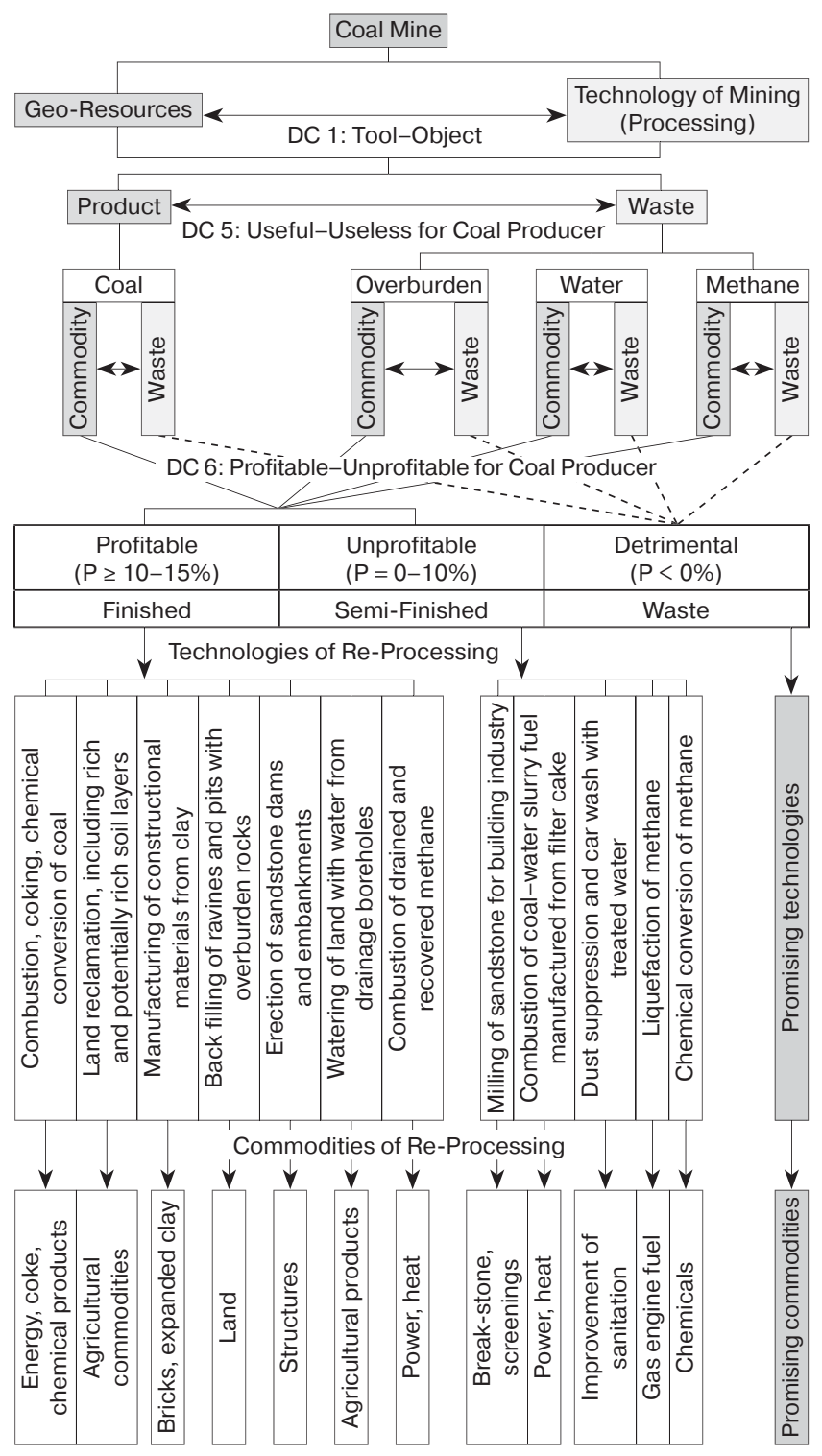

Fig. 3. Economic dialectical contradictions and resolutions in coal mining

is useless but unavoidable on the current technological level. The useful-useless relationship is adjusted through the selection of method, design, mode and schedule of mining.

Transition from a product to a commodity gives rise to DC 6: profitable-unprofitable for a coal producer (Fig. 3). Not everything useful (coal) is at the same time profitable as a commodity in the specific market conditions. Similarly, not everything useless (overburden, water, methane) is unprofitable given potentiality of conversion and utilization. Coal is converted into a product or a semi-finished product, and also, partly, to waste (low-grade, oxidized, burnt, diluted coal) detrimental for a mine. Process water pumped out of surface and underground mines is discharged to the hydrographic network (after treatment) as waste. In the meanwhile, water from drainage wells can be sold to farms for watering of agricultural land or for daily living needs of mining towns. Mine methane, removed by ventilation for many years, is now converted to a commodity for the power generation sector owing to innovative technologies [19, 20].

A mine dump is a storage for an altered unprofitable matter: overburden, low-grade coal, slime, stale and defective constructional materials, etc. The unprofitability ensues from the unfavorable state of mining business, damage of the product, imperfection of processing technologies and industrial backwardness. Modification of these conditions can turn the dump material to a man-made resource for addition production. For example, overburden dumps at open pit coal mines in Russia in the 1990s became the man-made deposits after development of the technology for coal and dirt separation in upward water flow in high-angle separators. Many millions of cubic meters of overburden rocks were reprocessed, which produced both extra coal and extra profit. Development of filter presses capable to dewater pulp slime converted slime reservoirs into storages of semi-finished products for the cost-effective manufacturing. Successful tests of the innovative coal-water slurry combustion technology put the earlier unprofitable semi-finished products of coal dressing (filter cakes) to the category of man-made resources [21]. Filter cakes become the basic material for the profitable production of coal-water slurry fuel for the further generation of heat and electric power and, thus, for the resolution of DC 7 (Fig. 1).

The innovative technologies of re-processing of georesouces enable resolving DC 6 and manufacturing of profitable goods from semi-finished products, waste rocks, water and gas (Fig. 3).

\section{Conclusions}

The analysis of the ecology-technology-dialectics connections provides an insight into the philosophical causes of the unfavorable environmental situation in the regions of coal mining. The dialectical contradictions inside the existing coal mining technologies only allow a coal mine to implement the georesource potential of a mining lease at a low scale, with loss of major natural capabilities. The key dialectical contradictions have physical and economical nature: objecttool, nature-technogenics, useful-useless and profitableunprofitable.

The fundamental modification of the immediate situation takes place in the framework of innovative proposals and $R \& D$ in the sphere of resolution of dialectical contradictions at all scales of mineral mining. The breakthrough solutions result from the resolution of these contradictions by changing operational policies in coal mining. The change in the operational policy in resolution of the object-tool contradiction of a coal mine makes it possible to put forward the method of underground energy "mining", which replaces the upward coal flow by the flow of energy fluids and eliminates the whole range of the adverse environmental and economic impacts. Improvement of the unfavorable ecological situation existing in coal mining regions calls for the fundamental renovation of approaches to coal production.

The deterrence of the activity and efficiency of innovations is largely governed by the recent reduction in the intelligent and innovation potential of coal mining engineers in Russia. Disclosure of the deep causes of the ongoing situation, 
dialectic sources, essences of contradictions and their resolutions to build up the mentioned potential is the trend of the further research of this study authors.

\section{Acknowledgments}

The article is prepared in the framework of the Competitive Power Improvement Program of the National Research Tomsk Polytechnic University.

References

1. Nifantov B.F. Coals with lucrative contents of chemical elements for the industrial extraction. GIAB. 2013. No. S6. pp. 111-121.

2. Trubetskoy K. N., Kaplunov D. R., Rylnikova M.V. Principles and methodological basis for the formation of a new technological system of sustainable development of underground ore mines in Russia. Fundamententalnye i prikladnye voprosy gornykh nauk. 2018. Vol. 5. No. 1. pp. 127-134.

3. Trubetskoy K. N., Galchenko Yu. Nature-Friendly Mining Technologies as a Condition of the Global Contradictions in the Development of Mineral Resources of the Lithosphere Resolution. Vestnik Rossiyskoy akademii nauk. 2017. Vol. 87. No. 7. pp. 655-662.

4. Makarishina Yu. I. Enhancement of ecological safety of overburden dumps at coal mines in Donbass using physical methods and revegetation : thesis of inauguration of Dissertation ... of Candidate of Agricultural Sciences. Lugansk, 2016. 145 p.

5. Ilkovskiy K. K., Timofeev D. I. View into the future power engineering. Gornyi Zhurnal. 2011. No. 12. pp. 73-74.

6. Rylnikova M. V. Man-made renewable sources of energy in subsoil development. Energiya: economica, tekhnika, ecologiya. 2016. No. 12. pp. 10-16.

7. Buravchuk N. I., Gurjanova O. V., Ajrapetjan M. A. Experience of Utilization of Breeds of Mine Spoils for the Device of a Roadbed. Izvestiya vysshikh uchebnykh zavedeniy. Severo-Kavkazskiy region. Tekhnicheskie nauki. 2007. Vol. 6. pp. 100-103.

8. Chumachenko N. G., Tyurnikov V. V., Petrova E. V., KhayrulIova D. V. Carbonate rock waste-a promising source of wade range constructional materials. Molodoy uchenyi. 2016. No. 10-6. pp. 143-146.

9. Schopenhauer A. The world as will and representation. Dover Publications, 2012.

10. Mikhalchenko V. V., Prokopenko S. A., Orlov V. G. Land-saving technology for thick steeply dipping and sloping coal seam mining. Ugol. 1991. No. 5. pp. 44-46.

11. Kovalenko V. S. Increase in efficiency of natural and manmade resources use in open coal mining within the framework of the concept of "green" mining industry. Ugol. 2018. No. 4. pp. 60-63.

12. Prokopenko S. A. From underground coal mining - to the coal power complexes. Gornyi Zhurnal. 2005. No. 11. pp. 8-10.

13. Rzhevsky V. V. Underground combustion of coal : teaching aid. Moscow : Moskovskiy gornyy institut, $1990.84 \mathrm{p}$

14. Kreinin E. V. Nonconventional thermal technologies of hard-torecover fuels : coal, hydrocarbons. Moscow : IRTS Gazprom, 2004. 302 p.

15. Prokopenko S., Sushko A., Filatov Yu., Kislyakov M., Kislyakov I. Environmental improvement of opencast mining. IOP Conference Series: Earth and Environmental Science. 2017. Vol. 50. 012012. DOI: 10.1088/1755-1315/50/1/012012.

16. Popov A. N., Lesin Yu. V. Using of artificial filter massifs for purification of open pit mine Shestaki waste water. GIAB. 2015. No. S1-1. pp. 560-568.

17. Lesin Yu. V., Luk'yanova S. Y., Tyulenev M. A. Formation of the Composition and Properties of Dumps at the Open-Pit Mines of Kuzbass. IOP Conference Series: Materials Science and Engineering. 2015. Vol. 6. 012093.

18. Chekmenev Yu. V., Fursa A. N., Chekmenev A. Yu. Mine methane application. Ugol. 2016. No. 5. pp. 78-81.

19. Taylakov O. V., Zastrelov D. N., Smyslov A. I., Utkayev E. A. Coal mine methane recycling in power plants at coal mines. GIAB. 2013. No. S6. pp. 170-176.

20. Ruban A. D., Zaburdyaev V. S., Artemev V. B., Loginov A. K., Yutyaev E. P. Technological Processes of Methane Recovery and Utilization at Mine Named by S. M. Kirov. Tekhnologii nefti i gaza. 2011. No. 3(74). pp. 46-51.

21. Noskov O. The process starts! Ugol Kuzbassa. 2016. No. 3 (050). pp. 84-86. 国

\section{Erratum}

Through inadvertence on the author's part, the article entitled: Design and industrial testing of innovative nonexpendable picks for cutter-loaders by V. V. Sementsov, S. A. Prokopenko, V. S. Ludzish, V. V. Abramov published in Eurasian Mining. 2019. No. 2. pp. 59-63. DOI: 10.17580/em.2019.02.13 contains an error in Acknowledgment.

The present form in this erratum is correct:

\section{Acknowledgment}

The article is prepared in the framework of the Competitiveness Enhancement Program of the Tomsk Polytechnic University. 